\title{
HISTORICAL TRAUMA BETWEEN EVENT AND ETHICS: ALEIDA ASSMANN'S THEORY IN THE CONTEXT OF TRAUMA STUDIES
}

\author{
Kseniya Kapelchuk \\ Saint Petersburg National Research University of \\ Information Technologies, Mechanics and Optics University ITMO \\ Sociological Institute of the Federal Center of Theoretical and Applied \\ Sociology, Russian Academy of Sciences \\ St Petersburg, Russia \\ ksenya_ka@list.ru
}

\begin{abstract}
The paper focuses on the way the notion of trauma functions and is justified in the contemporary discourse on history. The author refers to the works of Aleida Assmann and examines the critique brought forward against memorial culture. Deconstructing Assmann's argument, the author concludes that there are two levels of discourse that support and justify each other: the level of fact and the level of value. The first one deals with the problem of traumatic events and expanding memory about them, which is explained as a change of time regime. The second one deals with the ethical turn that made the change of the time regime possible. To analyse historical trauma, the article suggests breaking the connection between these two levels and examining their foundations separately.
\end{abstract}

Keywords: ethical turn, historical trauma, human rights, memory studies, philosophy of history, time, trauma studies

The basic questions that often arise in the context of a discussion about historical trauma and cultural memory are the following: is it really legitimate to use these constructs in historical studies and comprehension of the past on the one hand, and is it something useful for the present life on the other (Assmann 2013)? Despite the growing popularity of trauma and memory studies and their wide engagement in the social sphere, they still have to prove to the opponents their legitimacy and productivity in both the academic and cultural contexts. This tendency is distinctive for the so-called third wave of memory studies, which is identified as a reaction to the methodological critique of its basic notions and research strategies (Feindt et al. 2014; Safronova 2018). The situation with trauma studies is even more complex and problematic (Kansteiner \& Weilnböck 2008). 
In this paper I will examine answers to this critique given by Aleida Assmann, one of the most influential researchers of cultural memory and representatives of memory studies, and analyse the structure of the argument for the discourse of trauma. The discussion around it is multi-layered and the task I am going to perform is to bring out and deconstruct its theoretical foundations. In the first part I will consider Assmann's answer to the question of possibility and necessity of discourse about collective memory, or how we can talk about historical trauma. The second part concerns the question of the way we can describe this trauma. Here we can see that the way Assmann suggests justifying trauma discourse suffers from a tricky ambiguity: on the one hand, she explains the change of the perception of painful events of the past as the effect of the fall of the modern time regime, but on the other, the very establishment of the new time regime is explained as an effect of these painful events. Untying this knot, one can notice that the analysis of the nature of trauma as an event (as well as the justification of the discourse on historical trauma, as I show it in the first part of the paper) is based on some presuppositions of ethical nature. But as we can see in the third part of the paper, the ethical turn is not something unconditionally valuable itself. Thus, to see the whole construction of trauma in the context of the modern memorial culture as Assmann describes it, we should break the connection between ontological and ethical levels of description and examine their foundations separately.

\section{DISCONTENT AND CONTENTMENT WITH MEMORIAL CULTURE: THE POSSIBILITY OF HISTORICAL TRAUMA}

A thorough answer to the critique of the concept of collective memory and memorial culture was given by Aleida Assmann (2013) in her book Das neue Unbehagen an der Erinnerungskultur: Eine Intervention. One of the crucial arguments against the concept of collective memory concerns the metaphorical character of the notion of memory when it refers to a community. The discussion about this issue took place between Maurice Halbwachs and Marc Bloch already in the 1920s, yet it is still on the agenda today. As Jeffrey K. Olick writes: "It is perhaps somewhat disappointing, then, that we all still feel compelled to establish the social dimensions of memory again and again, which should really be old news by now" (Olick 2009). Assmann in her book answers to the argument of Reinhart Koselleck (2004b) and Jan Philipp Reemtsma (2010), who insist on an individual character of memory and who are extremely suspicious of memorial culture, seeing it as a sign of either collectivization and totalitarianism, or domination of a minority defending its interests (Assmann 2013: 24-27). ${ }^{1}$ 
Assmann refers to Koselleck's motto, "the task of the historian is not to form an identity, but to destroy it" (2004b: 28), which means that historical truth lies beyond the frame and normativity of memory, which is always contaminated with some interest. But to deny the social frameworks of individual memory and the role of symbolic function of culture because of its political consequences is to acknowledge that it somehow still exists. ${ }^{2}$ After all, it does not matter if commemoration is an individual act or a collective one, since it is an act of representation that functions according to certain rules.

It is never the past itself that acts upon a present society, but representations of past events that are created, circulated and received within a specific cultural frame and political constellation. Personal memories are purely virtual until they are couched in words or images in order to be communicated. Collective memories are produced through mediated representations of the past that involve selecting, rearranging, re-describing and simplifying, as well as the deliberate, but also perhaps unintentional, inclusion and exclusion of information. ... Disseminated by the mass media as interpretations or official definitions of historical events, representations are a powerful element in the construction, contestation and reconstruction of individual and collective memories. (Assmann \& Shortt 2012: 3-4)

The collective memory in Assmann's terms is not something abstract or fictional. It is one of the levels of human memory along with the individual or biological level as well as the social one. The point is that the collective memory is not something additional to the individual memory, but something indispensable for the latter's functioning.

The neural network is invariably linked to both dimensions: the social network and the cultural field. The latter includes material embodiment in the form of texts, visual images, as well as symbolic practices in the form of holidays and rituals. Biological memory is formed and developed through interaction with other people, just as it is formed and developed through interaction with cultural artifacts and acts. (Assmann 2006: 32)

What Assmann is trying to show to the critics of memory studies is that history should not be replaced by memory but supplemented by it. For Assmann the selective and hierarchical character of memory is compensated by a pluralistic approach to this subject in democratic states. Thus, such constructs as collective identity and collective memory are fully justified in the current cultural and political situation: 
Any memory is characterized by a particular perspective; memory is not biased and is determined by what is selected and what is excluded. In democratic countries the memorial community is never homogeneous ... In Germany there are many different 'we' with their collective memories: Germans as criminals responsible for the Holocaust; German Jews as victims of the Holocaust; Germans as victims of national socialism and World War II; Germans as victims of forced escape and deportations; Germans as victims of political persecution in the GDR; and finally, Germans from the families of former emigrants. And they all have different life stories. However, this does not exclude the presence of social memory frames, within which each of the listed groups places its own memory. (Assmann 2013: 28-29)

Another argument against the existing memory culture is based on the question of its value. Assmann's approach concerns the German situation and recognising their guilt but it can be extended to a broader context. The discontent that Aleida Assmann describes and comments on is twofold. On the one hand, it is discontent with the adherence to the past that replaces striving for the future (is the capacity to forget not less valuable than the capacity to remember?) and, on the other hand, the discontent with the subject and the form of commemoration. The past that returns is not some indifferent past; it is a set of traumatic events that have to be seen from the point of view of a victim. But if commemoration becomes a form of identification with the victim, it can be and often is interpreted as self-delusion. Moreover, the very expression of sympathy for victims is perceived as hypocrisy when it is performed in the form of a political ritual. In this context Assmann describes the situation in which the protest and the critical position of the leftist intellectuals became the source of German memorial culture as in the slogan "The victory is a defeat!" (Assmann 2013: 68). So memorial culture is questioned from at least three positions: Is it necessary to focus on the past instead of passing it? Is it necessary to construct collective identity from the negative moments of history? And is it justifiable to make a political performance out of suffering because in this case "memory is oblivion" (Assmann 2013: 70)?

In Assmann's commentary this knot finally turned out to be cut by the reference to the ethical turn and values of the politics of recognition. According to Assmann, there is no opposition between adherence to the past and facing the future; nor is there one between negative constitutive events and positive values: "the negative burden of history can be transformed into progressive values. ... The value of human dignity was born out of the ultimate humiliation of human dignity, so the positive meaning of this value remains linked to its negative genesis" (Assmann 2013: 74). The novelty is not excluded by the 
establishing of memorial culture; on the contrary, the very ethical requirement to include negative memory in the national identity is described by Assmann as an absolute historical innovation. Moreover, as she believes, "memory forges a new powerful link between past atrocities and a peaceful future" (Assmann $\&$ Shortt 2012: 1). The problem of ritualization of the commemoration in this regard is seen as some serious but inevitable and foreseeable challenge. The alienation of memory seems total only if we look at the top of the "memorial pyramid' with its politics and institutions, but the basis of the pyramid is society in all its diversity and variety. What really matters is the change within the moral framework:

With the recognition of the value of human rights, the political worldview itself has changed, focusing less on heroic warriors and more on civilian victims. At the centre of the political worldview there are no longer ideological utopias that rely on the 'new man', but the very vulnerability of human flesh, which has become the target of political, racist or sexist violence. (Assmann 2013: 95)

Thus the discourse of historical trauma has two levels that support each other: the level of fact and the level of value. To justify the first one, we need to appeal to the second one, and vice versa. But on what ground is the whole construction based? To address this problem, one should examine how the notion of trauma functions and through which theoretical procedures it sets in.

\section{EVENT AND REPRESENTATION: THE TIME OF TRAUMA}

What is substantial for the notion of trauma is its multi-valued nature. As Natalia Artemenko puts it, "different meanings [of trauma] do not share any common elements which would allow us to articulate what trauma really is, but they form a structure which Ludwig Wittgenstein calls a family resemblance" (Artemenko 2020: 5). Indeed, there are many definitions and interpretations of trauma that can be contradictory and controversial. Nevertheless, it does not dismiss the question about the basis of the discourse on trauma. What are the conditions - theoretical and political - that make a historical event marked as trauma? Something is happening with the time itself - it is 'out of joint'. This famous line from Shakespeare's Hamlet is used by Aleida Assmann in the title of her book Is Time out of Joint? On the Rise and Fall of the Modern Time Regime (2020). In this book Assmann gives a detailed analysis of the so-called tectonic shift in the contemporary sense of historicity, in our manner of dealing with time, the shift of the dominant temporal order. She refers to historian François 
Hartog, sociologist John Torpey, and philosopher Hans Ulrich Gumbrecht to describe the gap between the two time regimes, the gap which emerged in the 1980s and has determined our present-day experience of time, history, and identity (Assmann 2020: 175-200).

This new time regime marks the end of modernity, which conceived itself as the project directed to the future. For Assmann the transformation of the time regime is something self-evident, but at the same time enigmatic. "The future was the standard orientation; no one talked about the past. Just as we can no longer imagine people smoking in hospitals, it is now difficult for us to imagine how disinterested people were in the past" (Assmann 2020: vii). But what we have at our disposal for now is our past, which returns and refuses to go away. The basic intuition connects the phenomenon of trauma with a disturbance in the very texture of time. Aleida Assmann tries to demonstrate that historical trauma can be seen as an effect of the structural shift in the time regime. Some terrible historical events have become visible as a result of the structural transformation, which Assmann calls the fall of the modern time regime.

To clarify the meaning of the modern time regime we need to clarify the relation of the time regime to history. As a rule, history is described as a sequence of events, their mutual influences and connections, but our way to perceive history turns out to be historically conditioned. The very time has its history, and it becomes noticeable when a change in temporal frame occurs. What Assmann is trying to work with is the new experience of time we are facing today. Assmann uses the term 'time regime' or 'temporal regime' to describe a certain formation of historical experience or a certain way to configure the past, present, and future. Here she refers to the French historian François Hartog and his concept of 'regime of historicity' (Hartog 2015). For Hartog the regime of historicity "is a heuristic tool which can help us reach a better understanding not of time itself - of all times or the whole of time - but principally of moments of crisis of time, as they have arisen whenever the way in which past, present, and future are articulated no longer seems self-evident" (Hartog 2015: 16).

Assmann focuses on the crisis of the 1980s. She refers to the phenomenon of the so-called memory boom. The past suddenly fills the entire horizon of the conceivable. And this past is not really neutral or indifferent. The past returns to us as voices of victims, of those who suffered and demand recognition. The past returns to us as a trauma.

This time regime that became dominant from the 1980s onwards is opposed to the modern time regime, which expels the past as something inactual and outdated. The idea that the past is something that is separate from the present and can be left in the past belongs to modernity, which was invented in the Age of Enlightenment. In this regard Assmann partly follows Koselleck's theory: at 
the end of the eighteenth century history was singularized (Koselleck 2004a). This means that instead of premodern histories a history arose; "clear, engaging, concrete, exemplary, and often instructive histories were always histories of something; they were replaced in the course of singularization with an abstract and nonsensuous history" (Assmann 2020: 36). And this new concept of history produced a new understanding of time - an empty time that functions as a framework for events. Moreover, time "became the main engine driving historical change, emphasizing the new and disintegrating the old" (Assmann 2020: 37). According to Koselleck, the caesura took place around 1770 and initiated the development of modernization, but Assmann herself consolidates with those scholars who prefer to consider this process as discrete phases of modernization (Assmann 2020: 64-74). One of the last of these preceded the 1980s and took place in the 1960s-70s. To characterize it, Assmann quotes the novel Waterland by Graham Swift: "Once upon a time, in the bright sixties, there was plenty of future on offer" (Assmann 2020: 1). And then she adds: "At the time Swift was writing the novel, just two decades after the 'bright sixties', the future had lost its sheen; it had already turned into a 'past future"' (ibid.). So, we could say that the transition from the modern time regime to the contemporary time regime is the basic meaning of the phrase "the time is out of joint".

But the modern time regime was not invented from scratch either, because before there was another form of experience of time: the time of tradition, the time when it was the past that made the present and future comprehensible. The experience of time in the modern time regime presumes a hiatus between the past and the future, which is described by Koselleck as the division between a 'space of experience' and 'horizon of expectation'. The modern time regime is constituted by the separation and emancipation of the 'horizon of expectation' which makes the future independent and also valuable while the past becomes distant and depreciated. So, it is the modern time regime that produced "the collapse and reconfiguration of the past-present-future temporal structure" (Assmann 2020: vii). That is why the contemporary time regime can be interpreted by Assmann as the normalization of time: we are restoring the connection to our past, but in a new manner.

These ideas are beautifully combined in one theory and work as a credible way to explain the phenomenon of historical trauma, but this description suffers from a fundamental duality. On the one hand, Assmann speaks about a formal procedure, that is, a change in the manner we perceive the connection of the past, present, and future, the 'continental shift' in the structure of our time. But then she adds that "the burden of the violent histories of the twentieth century weighs heavily on the present, demanding attention and recognition and forcing us to take responsibility and to develop new forms of remembrance 
and commemoration" (Assmann 2020: 4). As one can see in the second step of the argument, Assmann gives an explanation of the 'continental shift' between time regimes, referring to the events that took place in the past. But is this step really legitimate? The thing is, originally we were talking about a time regime that performs a constitutive function in relation to a particular content of experience. But now we are following the reverse logic, assigning a constitutive role to events. That is, we are already moving within the perspective that has yet to be justified, and do not notice the difference between the fact and its meaning.

Furthermore, if the excess of violence in the history of the twentieth century determines the growing attention to the past, why did this attention and sensitivity to trauma come to us with a considerable delay? As we remember, "in the bright sixties, there was plenty of future". It turns out that a catastrophic event as such does not automatically entail the memorial boom. ${ }^{3}$

Another way to explain the change of the time regime Assmann resorts to is the following: "The future itself has lost the power to shed light on the present" (Assmann 2020: 3). But her explanation concerning the future preserves the same ambiguity as the first one discussed above.

Why have the stakes of the future fallen so drastically in value? Some obvious answers immediately come to mind: The resources of the future have been eroded by a number of complex challenges, such as the depletion of natural resources, the ongoing ecological degradation that accompanies technologically advanced societies, climate change, and water crises. These challenges, along with demographic problems such as overpopulation and aging societies, have fundamentally altered our image of the future. Under these conditions, the future no longer serves as the Eldorado of our hopes and dreams, while at the same time any heady talk about progress has begun to sound more and more hollow. (Assmann 2020: 3)

In other words, having declared a certain decline of the future as such, that is, a decline of a future-oriented time regime, Assmann immediately justifies it with the content of our anticipations of the future.

Such explanations justify each other, creating a vicious circle: the decay of the modern time regime allows us to conceive the past as traumatic, and at the same time it receives a justification as a consequence of traumatic events.

The critique of the confusion between the event and the manner of its representation was introduced by Jeffrey Alexander. He calls such a confusion a naturalistic fallacy and labels the theories that commit this fallacy 'lay trauma theories'. According to "lay theory, traumas are naturally occurring events that shatter an individual or collective actor's sense of well-being. In other words, the power to shatter - the 'trauma' - is thought to emerge from events themselves" 
(Alexander 2004: 2). According to Alexander's classification, we can talk about two types of lay trauma theories: enlightenment and psychoanalytic versions. The enlightenment version of a lay trauma theory understands trauma as an event located in the past, as a painful experience, with the consequences of which society is trying to cope in one way or another. Assmann's argument that "the burden of the violent histories of the twentieth century weighs heavily on the present, demanding attention and recognition" (Assmann 2020: 4) generally corresponds to this 'enlightenment' position. But Alexander's argument against such an approach is the following:

Events do not, in and of themselves, create collective trauma. Events are not inherently traumatic. Trauma is socially mediated attribution. The attribution may be made in real time, as an event unfolds; it may also be made before the event occurs, as an adumbration, or after the event has concluded, as a post-hoc reconstruction. Sometimes, in fact, events that are deeply traumatizing may not actually have occurred at all; such imagined events, however, can be as traumatizing as events that have actually occurred. (Alexander 2004: 8)

So, we should call the trauma not an event in itself, but rather its representation, whereas the lay trauma theory commits a naturalistic fallacy, that is, ascribes some external reasons to the social process of trauma. Alexander's own understanding of trauma can be described as 'cultural-sociological' because he defines trauma not as an event but as a social process.

Thus, the analysis of trauma theories proposed by Alexander allows us to identify the internal conflict of the interpretations of trauma. There is an overlapping of two perspectives: the first one explaining the event through the theory of time regimes, and the second one explaining the establishment of a time regime as an effect of the event. Alexander himself chooses a constructivist position, excluding the event from the discussion of trauma as something external to the 'process of trauma' and focusing on the conditions in which the trauma arises. But don't we commit a naturalistic fallacy of a different kind in this case? According to Alexander, "trauma is not the result of a group experiencing pain. It is the result of this acute discomfort entering into the core of the collectivity's sense of its own identity" (Alexander 2004: 10). Pain is replaced here by discomfort caused by the threat to identity, and this allows the replacement of the victim's figure by the collective actor who decides that such a threat exists. Instead of a single community experiencing an event, Alexander speaks of a 'group of carriers' whose goal is to represent the trauma claim convincingly to the audience-public. Thus, the history of trauma is reinterpreted by Alexander as a story of 'illocutionary success' when "members of this originating 
collectivity become convinced that they have been traumatized by a singular event" (Alexander 2004: 12). It turns out that the process of trauma, as in the lay trauma theory, is conditioned by some circumstances that are external to this process - in this case, by the discomfort, whose analysis remains principally beyond the consideration of the theory of trauma as representation.

Thus, having refused to explain the change in the temporal regime by a reference to an event, we still have not clarified the source of this very change. And here we can return to Assmann's work since it still provides one more alternative explanation for the expansion of the past. Assmann mentions that one of the conditions under which a historical event is transformed into a historical trauma is the fact that these events "were simply not approachable for the longest time, because no adequate cultural narratives were available" (Assmann 2020: 212). In Alexander's classification a similar formula belongs to the psychoanalytical trauma theory, which places trauma neither on the level of the event itself nor on the level of representation of this event, but between them. Cathy Caruth (1996), a representative of this approach, describes trauma as an 'unclaimed experience', referring to Freud's understanding of trauma:

Freud made a strange assumption that trauma consists of two stages. At an early stage (in childhood), trauma is characterized by a sexual content in the absence of sexual meaning for the child. The later stage (in adolescence) has no sexual content but acquires sexual significance. According to Freud, the relation between these two events creates the trauma: the event becomes a trauma retroactively. (Caruth 2009: 571)

As Caruth describes the trauma, belated recognition of trauma as trauma is the essence of the paradoxical figure of the 'unlocalizable event' (Caruth 2009: 572). While Alexander reduces the discussion about trauma to the discussion about the representation of trauma, then from Caruth's point of view trauma is neither an event nor a representation, but a failure of representation. And in this perspective it is already impossible to describe a trauma in terms of illocutionary success. In one of the interviews explaining the ambiguous nature of trauma, Cathy Caruth draws a line between the experience of trauma and the experience of a witness, saying: "the witness creates the addressee, the trauma erases it" (Suverina 2015). At the level of the witness, according to Caruth, we are surely dealing with various kinds of representations. Witness is associated with memory; memory defines the space of the historical. And in this sense, trauma and history are fundamentally different:

... traumatic repetition produces events that may look like historical events, but in the classical sense history is always associated with memory. That 
is, we need witnesses, and the descriptions that need to be read, and also it is necessary for us that witnesses realize that this is the past. Traumatic repetition is a death drive; it cannot be a historical event. It turns out that I want to go back and remember this event, but instead I just have to repeat it over and over again. (Suverina 2015)

It turns out that trauma operates at some fundamentally unspoken level which represents the basis for the witness, but it is important for Caruth to maintain this dual structure.

The fundamental difference between Caruth's and Assmann's positions in this context is that the latter connects the moment of the latent period, during which the trauma does not manifest itself as such, with a specific historical reason - the domination of the modern time regime. According to Assmann, it prevents the identification of trauma and working it through, forcibly keeping the past in the past. Assmann writes: "As long as the focus was exclusively on the future and on modernisation, the suffering and trauma of those who had to bear a significant share of the costs of this story of progress were systematically shielded from view" (Assmann 2020: 212). Thus, repression of the traumatic events, or 'historical wounds', as Dipesh Chakrabarty, to whom Aleida Assmann also refers, calls it, turns out to be historicized and explained in terms of ethics. The belatedness of trauma is interpreted here not as some structural moment of historical experience but as a consequence of the hegemony of the modern time regime values: "the future-oriented modern time regime silently passed over the victims of history" (Assmann 2020: 216). There is no place left for the differentiation between trauma and witness in this scheme. And in this moment one can see in what way an ontological level of analysis is based on the ethical ground. The radical change of the time regime, as Assmann recognizes, became possible due to the politics of recognition and the ethics of human rights. Thus, references to the ethical turn and politics of recognition act as an ultimate justification of trauma discourse in both cases: while examining why we can talk about collective memory and historical trauma, and also while analysing what historical trauma is. But what is the basis of this ethical turn?

\section{THE VICTIM AND HUMAN RIGHTS: ON THE CRITIQUE OF AN ETHICAL TURN}

In her works Assmann often responds to the criticism of the memorial culture and new time regime in terms of new ethics. For example, she debates one of the popular theses that the more victims of the repressive past are spoken of, 
the more the consensus between people with different backgrounds is likely to collapse. In this context Assmann suggests the conception of dialogical memory that not just divides people and nations, but also has potential to unite them due to transcending national borders through a transnational perspective, because "within the framework of memorial culture one of the fundamental human rights of individuals, social groups and national cultures is recognized - the right to their own vision of the world, experience and identity" (Assmann 2013: 205).

At the same time the answer to the critics of the axioms of such ethics is limited to the very short answer to Alain Badiou. In her Das neue Unbehagen an der Erinnerungskultur: Eine Intervention Assmann writes:

While continuing to praise the violence of 'heroic communism', Badiou looks with distaste at our modernity, where the values of family happiness and human rights dominate; he denounces this modernity as effeminate (feminine), politically exhausted and unviable. In contrast, the morality of those who see themselves as living in a post-ideological era is based on the value of individual human life, regardless of a person's national, cultural, or religious affiliation. The new memorial culture has entered into an alliance with a politics that protects human rights which have become a valuable foundation and guide for the future. (Assmann 2013: 96)

Thus, Assmann keeps in mind some critique of the values that she proposes, but from her point of view everything this critique is based on is some old violent ideology. ${ }^{4}$

Here we should look closer at the alternative interpretations of the 'ethical turn' that has led to the re-evaluation of the past and traumatic experience. While Assmann looks at the bright side of this event, such thinkers as Alain Badiou, Jacques Rancière, and Giorgio Agamben are deeply concerned about its implications even if taking different positions on many issues. As Assmann notices, an ethical turn puts in the forefront "vulnerability of human flesh, which has become the target of political, racist or sexist violence" (Assmann 2013: 95). To be recognized as a subject, this flesh should claim its identity, and after the ethical turn can thus count on protection. The latent axioms of this position are the following: 1) human being is defined as a body that suffers, enjoys, dies, and is also capable of engaging in a dialogue and reaching some consensus; 2) the ethics of human rights should somehow consider interests of those people whose rights are (or were) violated and who cannot fight for themselves.

The first idea totally corresponds to the so-called democratic materialism described by Badiou. According to democratic materialism, "there are only bodies and languages" (Badiou 2005: 20). But there is something lacking in the situation when "the law protects all the bodies, arranged under all the compatible 
languages" (Badiou 2005: 22), and according to Badiou it is the truths. What must be opposed to democratic materialism is a materialist dialectic that states that "there are only bodies and languages, except that there are truths" (Badiou 2005: 22). One of the purposes of Badiou's essay on ethics is to suggest some alternative to the ethics based on human rights and eventually define man as "the being who is capable of recognizing himself as a victim" (Badiou 2001: 10). The ethics that put forward such a description of man, according to Badiou, eventually reduce the human being to less than man, that is, to a suffering beast and dying body, whereas everything that really matters even in an extreme and traumatic situation is this "almost incomprehensible resistance on the part of that which, in them, does not coincide with the identity of victim" (Badiou 2001: 11). The fact that man thinks and "is a tissue of truths" endows them with a kind of immortality and requires another ethic - an ethic of truths. Without this element all we have is the ethics of a finite creature that can derive the Good only from the Evil, because "human rights' are rights to non-Evil: rights not to be offended or mistreated with respect to one's life (the horrors of murder and execution), one's body (the horrors of torture, cruelty and famine), or one's cultural identity (the horrors of the humiliation of women, of minorities, etc.)" (Badiou 2001: 9).

Such ethics for Badiou just legitimates the "conservatism with a good conscience": the ethics of consensus "is inconsistent, and ... reality of the situation is characterized in fact by the unrestrained pursuit of self-interest, the disappearance or extreme fragility of emancipatory politics, the multiplication of 'ethnic' conflicts, and the universality of unbridled competition" (Badiou 2001: 10).

Besides, one of the consequences of such ethics is the transformation of the right "of the living being to remain a desolate individual aspiring to enjoyment" to the "right to intervention" (Badiou 2005: 20-21). This right inevitably arises from the absolute right of the victim that is also analysed by Rancière. Thus, the new legal situation is not the empowerment of victims and increasing attention to their rights, but "disappearance of right itself" (Rancière 2006: 7). Structurally it is based on the indistinction between fact and right, which is doubled by the indistinction of political 'people' and population. When it comes to trauma and victims, ethics appeals to the human rights, but they become "the specific rights of those who were unable to exercise those rights. As a result, the following alternative presented itself: either these human rights no longer meant anything, or they became the absolute rights of those without rights, that is to say rights demanding a response which was itself absolute, beyond all formal, juridical norms" (Rancière 2006: 7-8).

This directly corresponds with the second axiom of the ethical turn mentioned above, but in the case of Rancière this statement does not look so optimistic. Its 
reverse side is endless humanitarian war "that is not a war, but a mechanism of infinite protection, a way of dealing with a trauma elevated to the status of a civilizational phenomenon" (Rancière 2006: 8).

The problem is that for human rights to be realized they should be supported and guaranteed by some social structure, the state. That is why a human, in order to have rights, must be also "something other than a 'human", that is - a citizen (Rancière 2006: 9). The radical change that happened along with the ethical turn is the change in this inhuman surplus that is now "that part of ourselves that we do not control, a part that takes on several figures and several names: the dependence of the child, the law of the unconscious, the relationship of obedience towards an absolute Other. The 'inhuman' is that radical dependence of the human towards an absolutely other whom he cannot master. The 'right of the other' then is the right to witness this subjection to the law of the other" (Rancière 2006: 9).

Thus, a human reduced to a body, cleared from ideologies and appealing to have human rights, invokes a sovereign.

A thorough analysis of the connection of a bare life and a sovereign was given by Giorgio Agamben in his famous Homo Sacer project. In the first book of this series, Homo Sacer: Sovereign Power and Bare Life (Agamben 1998), he traces how two senses of 'life', distinguished in Greek as "zoē, which expressed the simple fact of living common to all living beings (animals, men, or gods), and bios, which indicated the form or way of living proper to an individual or a group" (Agamben 1998: 9), were unfolding and intertwining in European history and politics that finally turned into biopolitics. The emancipation of a body and a concern about its pleasures and suffering being placed in the centre of political life represents nothing but the production of a biopolitical body, which is the original act of sovereign power. The biopolitical body can be described as homo sacer, who is totally excluded from both human and divine law, who may be killed and yet not sacrificed. When it comes to the protection of the population (one of the main functions of biopolitics), everyone eventually tends to be the one as the state of emergency becomes the rule.

That is why Agamben also criticizes modern democracy and the ethics of human rights.

If anything characterizes modern democracy as opposed to classical democracy, then, it is that modern democracy presents itself from the beginning as a vindication and liberation of zoe, and that it is constantly trying to transform its own bare life into a way of life and to find, so to speak, the bios of zoē. Hence, too, modern democracy's specific aporia: it wants to put the freedom and happiness of men into play in the very place - 'bare life' - that marked their subjection. (Agamben 1998: 13) 
The struggle for the victims who are treated in terms of suffering of the human flesh paradoxically brings the opposite effect.

\section{CONCLUSION}

The critique of the ethical foundation of the contemporary time regime as Assmann describes it puts into question the evaluation of the social processes connected to this issue. Yet, it does not decrease its significance and, on the contrary, exposes its enigmatic character. Our way to deal with time has changed, but what does it say about us? The explanation in terms of time regime, ethical turn, and humanization is undoubtedly useful and insightful in particular contexts, but in general it represents a rationalization of the situation. And one of the insistent motifs that is stressed in the framework of such a rationalization concerns the idea that traumas are returning from the past as memories about them. However, if we abandon the enlightenment theory of trauma in Alexander's terms, it will be clear that we should not look for the answer in the past. The very impossibility to leave the present besieged by the past can be seen as a symptom of the trauma that was not really reflected because we are constantly confusing the trauma and the witnessing. If the latter is compelled to remember, the former is condemned to the "endless inherent necessity of repetition" (Caruth 1996: 63). Such a repetition manifests itself not by the commemoration, but by the "cry 'May that never happen again!' when it is clear that 'that' is, by now, everywhere" (Agamben 1999: 20).

The notion of historical trauma is indeed influential nowadays. At the same time the widespread criticism it gets is justified but, as a rule, is of restrictive character. It can be easily crushed by mutually supportive historical and ethical arguments as pointed out above in the case of Assmann's rhetoric. Moreover, this rhetoric also contains another circular reasoning that concerns the theory of time regimes which explains the way of an event's representation as traumatic and at the same time is explained by these events. This makes the whole construction vulnerable. Exposing the fact that the ontological level of the argument is based on the ethical ground, I have demonstrated that the fundamental discussion about trauma discourse should concern the value of the notions of ethical turn, human rights, and biopolitics. This kind of critique not only touches the core of the theory of historical trauma but also provides an opportunity for a deeper reflection of the current situation and our focus on the experience of the victim. 


\section{ACKNOWLEDGEMENTS}

This study was funded by the Russian Foundation for Basic Research (RFBR), project number 18-011-00570.

\section{NOTES}

1 The critique of the memorial culture by Reemtsma, presented in the paper Wozu Gedenkstätten? (Why memorials?), concerns a broader context than Assmann describes here, but Assmann touches upon the specific aspects of the discussion. Reemtsma's attention is focused on the "dilemma of "memory": we are searching for the meaning and foundation, "trying to learn from history who we are and what we can hope for", but at the same time this demand addresses historiography that is not able to fulfil the task and answer such questions. Reemtsma's core argument against the requirement not to forget is the following: one demands from history more than it can accomplish - to create meaning (Reemtsma 2010). It is peculiar that Assmann quotes the passage in Reemtsma's paper about the desire to learn from history who we are and what we can hope for, but only in a positive sense and not a controversial one, while for Reemtsma, as he claims at the very beginning of the article, "[i]t is not about memory, it is about consciousness and shame" (Reemtsma 2010).

2 In this context Koselleck prefers to speak not about 'collective memory', but about 'collective conditions' of memories (2004b: 28).

${ }^{3}$ Assmann explains this situation in New Discontent with Memorial Culture: Intervention as a conflict between generations. Here she refers to the German experience of World War II: the invocation to remember was a reaction of the generation of 1968 to the silence of those who directly participated in the event and chose to forget to move on.

The war generation got rid of its past by drawing a final line, and the second generation marked this past with a moral dividing line. The pragmatic final line meant getting rid of the past by silence; the corresponding psychological attitude was: 'Don't say a word about it!' On the contrary, the moral dividing line meant distancing from the past; in this case, the attitude proclaimed: 'We are different, so we must talk about the past!' (Assmann 2013: 49)

On the one hand, this explanation can be read as a denial of the assumption that the reason for a change of the time regime is rooted in certain catastrophic events. On the other, even here Assmann adds that "the politics of silence and drawing the final line, which justified itself after the symmetrical violence of civil wars, did not work in the case of a radical asymmetry in the use of extreme violence" (Assmann 2013: 200). That is the reason why turning to the past is still considered to be a traumatic event. So, the position of the author remains ambiguous.

${ }^{4}$ Badiou in his turn would not agree to such a profile. In Ethics: An Essay on the Understanding of Evil he ardently engages in the polemics with the ethics of human rights:

When those who uphold the contemporary ideology of 'ethics' tell us that the return to Man and his rights has delivered us from the 'fatal abstractions' inspired by 'the ideologies' of the past, they have some nerve. I would be delighted to see today so 
constant an attention paid to concrete situations, so sustained and so patient a concern for the real [le réel], so much time devoted to an activist inquiry into the situation of the most varied kinds of people - often the furthest removed, it might seem, from the normal environment of intellectuals - as that we witnessed in the years between 1965 and 1980. In reality, there is no lack of proof for the fact that the thematics of the 'death of man' are compatible with rebellion, a radical dissatisfaction with the established order, and a fully committed engagement in the real of situations [dans le réel des situations], while by contrast, the theme of ethics and of human rights is compatible with the self-satisfied egoism of the affluent West, with advertising, and with service rendered to the powers that be. (Badiou 2001: 7)

\section{REFERENCES}

Agamben, Giorgio 1998. Homo Sacer: Sovereign Power and Bare Life. Transl. by Daniel Heller-Roazen. Stanford: Stanford University Press.

Agamben, Giorgio 1999. Remnants of Auschwitz: The Witness and the Archive. Transl. by Daniel Heller-Roazen. New York: Zone Books.

Alexander, Jeffrey C. 2004. Toward a Theory of Cultural Trauma. In: Jeffrey C. Alexander \& Ron Eyerman \& Bernhard Giesen \& Neil J. Smelser \& Piotr Sztompka (eds.) Cultural Trauma and Collective Identity. Berkeley \& Los Angeles \& London: University of California Press, pp. 1-30.

Artemenko, Natalia (ed.) 2020. Topologiia travmy: Individual'nyi travmaticheskii opyt $i$ opyt istoricheskikh katastrof. [Topology of Trauma: Individual Traumatic Experience and Experience of Historical Catastrophes.] Saint Petersburg: Renome.

Assmann, Aleida 2006. Der lange Schatten der Vergangenheit: Erinnerungskultur und Geschichtspolitik. Munich: C.H. Beck.

Assmann, Aleida 2013. Das neue Unbehagen an der Erinnerungskultur: Eine Intervention. Munich: C.H. Beck.

Assmann, Aleida 2020. Is Time Out of Joint? On the Rise and Fall of the Modern Time Regime. Transl. by Sarah Clift. Ithaca \& London: Cornell University Press \& Cornell University Library.

Assmann, Aleida \& Shortt, Linda (eds.) 2012. Memory and Political Change. Basingstoke: Palgrave Macmillan.

Badiou, Alain 2001. Ethics: An Essay on the Understanding of Evil. Transl. by Peter Hallward. London \& New York: Verso.

Badiou, Alain 2005. Democratic Materialism and the Materialist Dialectic. Radical Philosophy, Vol. 130, pp. 20-24. Available at https://www.radicalphilosophyarchive. com/issue-files/rp130_article2_democraticmaterialismmaterialistdialectic_ badiou.pdf, last accessed on 15 April 2021.

Caruth, Cathy 1996. Unclaimed Experience: Trauma, Narrative, and History. Baltimore \& London: The John Hopkins University Press.

Caruth 2009 = Karut, Keti. Travma, vremia i istoriia. [Trauma, Time, and History.] In: S. Ushakin \& E. Trubina (eds.) Travma:punkty. [Trauma:Points.] Moscow: Novoe literaturnoe obozrenie, pp. 561-581. Available at https://www.academia. edu/462329/, last accessed on 15 April 2021. 
Feindt, Gregor \& Krawatzek, Félix \& Mehler, Daniela \& Pestel, Friedemann \& Trimçev, Rieke 2014. Entangled Memory: Toward a Third Wave in Memory Studies. History and Theory, Vol. 53, No. 1, pp. 24-44. https://doi.org/10.1111/hith.10693.

Hartog, François 2015. Regimes of Historicity: Presentism and Experiences of Time. Transl. by Saskia Brown. New York: Columbia University Press.

Kansteiner, Wulf \& Weilnböck, Harald 2008. Against the Concept of Cultural Trauma (or How I Learned to Love the Suffering of Others Without the Help of Psychotherapy). In: Astrid Erll \& Ansgar Nünning (eds.) Cultural Memory Studies: An International and Interdisciplinary Handbook. Berlin \& New York: de Gruyter, pp. 229-241. https://doi.org/10.1515/9783110207262.4.229.

Koselleck, Reinhart 2004a. Futures Past: On the Semantics of Historical Time. Transl. by Keith Tribe. New York: Columbia University Press.

Koselleck, Reinhart 2004b. Gibt es ein kollektives Gedächtnis? Divinatio, Vol. 19, pp. 23-28.

Olick, Jeffrey K. 2009. Between Chaos and Diversity: Is Social Memory Studies a Field? International Journal of Politics, Culture, and Society, Vol. 22, pp. 249-252. https://doi.org/10.1007/s10767-009-9059-7.

Rancière, Jacques 2006. The Ethical Turn of Aesthetics and Politics. Critical Horizons, Vol. 7, No. 1, pp. 1-20. http://dx.doi.org/10.1163/156851606779308242.

Reemtsma, Jan Philipp 2010. Wozu Gedenkstätten? Aus Politik und Zeitgeschichte, Vol. 25-26. Online. Available at https://www.bpb.de/apuz/32663/wozugedenkstaetten? $\mathrm{p}=0$, last accessed on 15 April 2021.

Safronova, Julia 2018. Tret'ia volna memory studies: dvadtsat' tri goda protiv shersti. [The Third Wave of Memory Studies: Going Against the Grain for Twenty-three years.] Politicheskaia nauka, No. 3, pp. 12-27. Available at http://inion.ru/site/ assets/files/3362/safronova.pdf, last accessed on 15 April 2021.

Suverina, Ekaterina 2015. Arkhiv, sobytie i istoricheskaia travma. Interv'iu s professorom Kornell'skogo universiteta Keti Karut. [Archive, Event, and Historical Trauma. Interview with Professor of Cornell University Cathy Caruth.] Laboratoriia publichnoi istorii, 14 January. Available at http://publichistorylab.ru/archives/176, last accessed on 15 April 2021.

Kseniya Kapelchuk is Assistant Professor at the Institute of International Development and Partnership at the ITMO University, Russia, and Associate Research Fellow at the Sociological Institute of the Federal Center of Theoretical and Applied Sociology of the Russian Academy of Sciences. Her main research areas are philosophy of history, historical trauma, repetition and philosophy of cinema.

ksenya_ka@list.ru 